\title{
Ginástica, higiene e eugenia no projeto de nação brasileira: Rio de Janeiro, século XIX e início do século XX
}

Edivaldo Góis Júnior*

\begin{abstract}
Resumo: O objetivo deste estudo foi descrever a influência dos saberes médicos sobre a organização da Ginástica escolar no século XIX no Brasil. Para isto, utilizou como fontes: as teses para a obtenção do título de doutor da Faculdade de Medicina do Rio de Janeiro e da Bahia; documentos da Academia Nacional de Medicina e da Escola Normal de São Paulo. Concluiu que a mentalidade higienista foi fundamental para a difusão da Ginástica no contexto brasileiro.

Palavras-chave: Ginástica. História. Brasil. Higiene. Eugenia.
\end{abstract}

\section{INTRODUÇÃO}

A sistematização da Ginástica do século XIX é um evento que não se explica por si só, embora tenha uma história própria e específica, ela influencia e é influenciada por um contexto mais amplo que envolve a história cultural, política e econômica. Não temos neste ensaio a pretensão de construir uma narrativa que se caracterize por uma história total. Muito menos dar base a uma história estruturante, onde as personagens são passageiras de uma história definida pela economia. Almejamos sim, analisar as fontes tendo como centro a mentalidade das personagens sobre os critérios para a organização de uma ginástica racional identificada com a ciência e com um projeto de nação.

"Professor Adjunto da Faculdade de Educação, Centro de Filosofia e Ciências Humanas da Universidade Federal do Rio de Janeiro, Rio de Janeiro, RJ, Brasil. E-mail: egoisjunior@gmail.com 
A descrição de uma mentalidade própria e especifica de um período, de um grupo de intelectuais, é datada. Mentalidade é uma noção vaga, ambígua, mas, segundo Le Goff (2005) é um dos conceitos que mais deu oxigênio à história. Descrever uma mentalidade exige a desconstrução de um modelo estruturante que seja reproduzido em diversos contextos, mas ao contrário, perceber as especificidades de dada sociedade, em determinado tempo. "A diferença torna-se então a condição da particularidade, e da inteligência da particularidade: ela separa essa cultura da nossa e assegura-lhe uma originalidade." (ARIÈS, 2005, p. 231)

Desse modo, buscamos compreender uma mentalidade do passado que não tem relação direta com o presente. Neste caso, o hoje da Educação Física apenas suscitou a problematização. A partir daqui apenas nos interessa a reconstrução desta mentalidade do passado, ou seja, vislumbrar as relações entre a institucionalização e escolarização da Ginástica mediante uma mentalidade científica, médica e higienista envolta em um projeto de nação.

Enfim, nosso objetivo foi descrever a influência de saberes médicos sobre a organização da Ginástica como prática corporal escolarizada no contexto do século XIX e início do século XX no Brasil. Para isto, utilizamos como fontes: as teses para a obtenção do título de doutor da Faculdade de Medicina do Rio de Janeiro que dataram do século XIX; ofícios e atas da Academia Nacional de Medicina. O critério de seleção dos documentos obedeceu à tematização central da Ginástica relacionada à higiene, saúde e educação física. Os documentos foram delimitados também por uma periodização definida pelo século XIX e início do século XX, especificamente, até a década de 1910. A pesquisa foi realizada nos acervos da Academia Nacional de Medicina, da Biblioteca do Centro de Ciências da Saúde (Universidade Federal do Rio de Janeiro), da Biblioteca Nacional, na cidade do Rio de Janeiro.

A análise dos documentos embasou a construção de uma narrativa que inicialmente contextualiza o debate higienista brasileiro, vislumbrando o debate racial e sua heterogeneidade, mas revelando também uma mentalidade homogênea em relação à necessidade de 
intervenção governamental nos problemas sociais do país. A partir deste ponto, debate como esta premissa colaborou na disseminação de novas práticas corporais, em específico, a Ginástica.

\section{RAÇA, HIGIENE E PROJETO DE NAÇÃO}

No Brasil oitocentista, os médicos a partir dos argumentos de defesa da ciência passam a determinar a melhor forma para cada um cuidar de seu corpo, em um projeto de mudanças de hábitos em relação a ele, o que passaria pela necessidade de construção de projetos nacionais nos campos da Saúde e Educação que foram idealizados no contexto do século XIX. Gondra (2004) ao analisar as teses da Faculdade Medicina do Rio de Janeiro nos anos oitocentistas revela o papel idealizado de uma sociedade saudável planejada pelos intelectuais da Saúde. Nesse caso, sobretudo dos médicos em uma orientação de políticas educacionais que sustentasse um projeto nacional de modernidade.

O Brasil no século XIX era um país com cidades desestruturadas e grandes diferenças entre o litoral e o interior, embora houvesse $\mathrm{o}$ desejo de urbanização e desenvolvimento a partir de um modelo europeu. No mesmo período, os principais países europeus já viviam um processo de crescimento do capitalismo industrial, manufatura e grande indústria, principalmente, a Inglaterra, França e Alemanha (RABINBACH, 1992). Este quadro de constante crescimento da indústria e da pobreza constituiu um cenário propenso às reformas de vários setores da sociedade. Mas este não foi o único aspecto que caracterizou o cenário europeu, também foi relevante o aumento do poder por parte de intelectuais influenciados pelo cientificismo, como médicos, advogados, engenheiros, educadores. Vários profissionais começaram a disseminar seus discursos de melhoria dos padrões de vida. As pesquisas científicas eram o argumento de autoridade deste ideário que comprovavam a urgência na intervenção da sociedade nos problemas da população. Como resultado deste processo, o surgimento da ciência do trabalho colaborou na redução da jornada, e em melhores condições de vida para o trabalhador 
(RABINBACH, 1992). Já no Brasil dos anos de 1800, as mesmas concepções ainda estavam distantes. O país tinha uma economia agrária e escravocrata. Por isso, por aqui o discurso de identidade nacional, de raça, de formação do povo era mais pertinente. Ele era sustentado pelo "racismo científico" da época, caracterizando um pessimismo, claramente herdado de alguns intelectuais europeus (MARQUES, 1997), e que no Brasil tinha uma repercussão sobre a construção da identidade nacional no século XIX.

Mesmo assim a incorporação de ideias estrangeiras pelos nossos intelectuais não foi mecânica, pois havia contradições embasadas em um nacionalismo dos médicos brasileiros, e pela crença na formação do povo pela educação e saúde.

Edler (2002) nos explica que este cenário do ambiente médico brasileiro da época era herdeiro de uma multiplicidade de práticas, conceitos e métodos. Para este historiador da medicina, no século XIX no Brasil tínhamos principalmente três grupos em disputas: o ligado à anatomoclínica, outro à topografia médica, e um terceiro ligado à medicina experimental. $\mathrm{O}$ primeiro tinha como espaço institucional característico o hospital; o segundo grupo era considerado representante de uma medicina de gabinete, em virtude do uso do método estatístico, por isso assimilado com reservas, e o último, o da medicina de laboratório, apresentou-se no cenário científico, desafiando francamente a forma de produção do saber médico. Edler (2002) destaca que no Rio de Janeiro, várias sociedades e periódicos médicos, postularam a necessidade de se incrementarem as pesquisas sobre os nossos males, visando reabilitar a imagem insalubre do Império perante as nações europeias. Assim, segundo Edler (2002), os médicos brasileiros oitocentistas incentivavam e divulgavam a produção científica local, onde novas ideias sobre as etiologias parasitárias se misturavam com as etiologias climatológicas e raciológicas a partir da segunda metade da década de 1860.

A influência desta heterogeneidade de práticas e teorias envoltas sobre os saberes médicos produziu um discurso sobre raça específico no debate brasileiro. Em outras palavras, ao mesmo tempo em que negava teses europeias sobre raça como as de Arthur de Gobineau 
(1816-1882), conservava uma tendência para o embraquecimento da raça através da mestiçagem. Um médico que representa este pensamento no fim do século XIX e início do século XX foi Afrânio Peixoto (1876-1947). Médico baiano, que fez carreira no Rio de Janeiro, foi membro da Academia Brasileira de Letras, foi professor de História da Educação e reitor da Universidade do Brasil. Ele, também, escreveu contra as ideias pessimistas em relação ao futuro do Brasil, contidas nas explicações deterministas (raciais e climáticas). Peixoto era um intelectual que apesar de seu nacionalismo, na tentativa de refutar as teorias pessimistas em relação ao Brasil, era um autor que não se desprendia do racismo das teorias que criticava. Pois vislumbrava em sua obra que o Brasil necessitava também de um embranquecimento da raça. Mas não como se fez nos Estados Unidos, com estratégias restritivas. Ele dizia que as imigrações: "nos dão esperança de uma mestiçajem proxima dos europeus, integrados no tipo branco. [sic]" (PEIXOTO, 1913, p. 359). Ele julgava o embranquecimento um fato positivo para o Brasil, mesmo sendo proveniente das misturas de raças, o que era condenado pelos eugenistas americanos. Para estes, esta mistura degeneraria a raça branca. (SKIDMORE, 1998). Já Peixoto achava que a mistura de raças poderia embranquecer o país. Apesar de ser um higienista que via na Educação do povo uma intervenção impreterível, ele é influenciado pelos determinismos que criticava. Contudo o debate racial da eugenia não se restringia somente à questão da etnia, envolvia outras questões como constituição física, força individual e coletiva de uma nação.

Por exemplo, na Europa, o debate sobre a constituição do povo também era controverso no campo da medicina. Enquanto na Inglaterra, Francia Galton (1822-1911) criava o conceito de eugenia negativa, ou seja, seleção genética artificial das pessoas mais saudáveis através da esterilização e regulamentação de casamentos, diferentemente na França, a eugenia negativa foi fortemente criticada por uma cultura católica que via na esterilização de doentes um método anticoncepcional que atentava contra a vida. Na França já no fim do século XIX, a eugenia foi mais influenciada pela puericultura de Adolphe Pinard (1844-1934), que defendia a qualidade da gestação 
e dos cuidados com a criança para o desenvolvimento de uma população mais saudável conhecida como eugenia positiva (DIAS, 2008). Ou seja, o eugenismo francês concentrou-se mais em medidas preventivas e educacionais. O Brasil se aproxima da França, mas durante o século XIX, o debate sobre a formação do povo brasileiro era intenso. Assim no Brasil, alguns médicos defendiam medidas mais restritivas como a esterilização dos doentes e regulamentação dos casamentos. Porém essa eugenia negativa não foi empregada pelo Estado brasileiro, pois no campo da medicina havia seus defensores e opositores. Por exemplo, um dos opositores foi o médico mineiro João da Matta Machado. Ele defendeu uma tese intitulada "Educação physica, moral e intelectual da mocidade do Rio de Janeiro e sua influência sobre a saúde", defendida no Rio de Janeiro em 1874. Sobre a regulamentação de casamentos, dizia firmemente:

Só um estado morbido characterisado deverá constituir impedimento ao matrimonio; separar dous corações que se amam, impedir a sua união só por meras considerações de melhoramento da especie, seria a mais cruel das tyranias, seria mesmo equiparar o amor ao instincto da reprodução, isto é, colocar no mesmo gráo o homem e o animal.

[...] Quando a predisposição morbida hereditaria se manisfesta, ou mesmo quando os paes sofrem molestias transmissíveis por herança, a hygiene deve aplicar os meios de que dispõe para neutralisar os perniciosos efeitos da hereditariedade. São elles em resumo os seguintes: um aleitamento que satisfaça todos os requisitos exigidos [...] um regimen alimentar conveniente ás suas circunstancias, a habitação em um clima saudavel, [...]; finalmente submetter o menino a processos hygienicos diversos, conforme predisposição que apresenta, continuando-os por longos anos, até que se tenha conseguido modificar completamente a sua natureza. (MACHADO, 1874, p.38-9)

Observamos uma influência do determinismo hereditário como fomentador de diversas moléstias, mas também a influência da crença de que a puericultura e uma educação bem orientada nos preceitos médicos poderia aperfeiçoar a saúde individual. 
Mas as observações de Machado não se esgotam no aperfeiçoamento do indivíduo, em diversos momentos na tese, ele analisa o Brasil em comparação com outras nações. Enfatizava que a educação higiênica poderia proporcionar o aperfeiçoamento físico coletivo e individual. Também destacava que o projeto higienista estava distante da realidade brasileira, atacando o governo imperial (MACHADO, 1874). Criticava a educação dos colégios brasileiros influenciada pela cultura religiosa. Com isso, apontou para a necessidade de uma educação voltada para os interesses da ciência e da nação. Para o médico, a Educação se definia da seguinte forma:

A educação, que se póde definir a arte que se aplica a dirigir a influencia das causas externas e internas para um fim determinado e preconcebido, se encarrega desde esse momento de fazer desenvolver aquelle germen, protegendo-o efficazmente contra a influencia das causas exteriores ou dirigindo-as para um fim determinado, - o aperfeiçoamento do individuo. (MACHADO, 1874, p.17)

Percebemos nesta tese médica do século XIX a presença dos determinismos hereditários e climáticos das moléstias, em voga no período, mas ressaltava-se também a Educação como ferramenta que poderia amenizar ou corrigir as predisposições. Dentre diversas estratégias higienistas, Machado (1874) destaca o exercício físico na Educação:

O exercício moderado, regular e methodico continuado por longo tempo, e auxiliado por uma alimentação conveniente e um clima salutar, póde modificar as predominancias pouco hygienicas, transformando indivíduos lymphaticos ou nervosos em belos typos do temperamento sanguíneo; vence s predisposições morbidas e aniquilla até a perniciosa influencia da hereditariedade. (MACHADO, 1874, p. 48)

Se João da Matta Machado colocou com central a prática específica do exercício físico, também orientou como deveria ser sua prática, elogiando a ginástica científica, e evidenciando a desestruturação da ginástica escolar, cobrando do governo imperial 
uma intervenção sobre o assunto (MACHADO, 1874). É interessante perceber que Machado (1874) revela que sua defesa de tese foi presenciada pelo Imperador Dom Pedro II, que ouviu as seguintes críticas em relação ao cenário nacional da ginástica nas escolas:

Infelizmente nos collegios brasileiros a gymnastica é completamente desprezada; não nos admiramos que os diretores se olvidem de tão precioso recurso, o governo, porém, que centralisa tudo, que clama a si o direito de velar pela instrucção da mocidade [...] não se anima a tornar a gymnastica obrigatória em todos os estabelecimentos de educação! (MACHADO, 1874, p. 55)

Mesmo na capital do Império, ressalta Machado:

[...] é verdade, existe uma aula de gymnastica que funciona uma ou duas vezes na semana; durante as lições, que grande numero de alunos assiste, um ou outro pratica certas evoluções enquanto que a grande maioria se distrahe conversando ou brincando. Assim comprehendida a gymnastica não produz os resultados favoráveis que se devia esperar, tornase objeto de luxo, simplesmente para inglez ver, como diz o proverbio. (MACHADO, 1874, P. 80-1)

Mesmo que os médicos brasileiros tivessem características bastante heterogêneas em relação aos métodos, teorias e ideologias, eles eram homogêneos na cobrança do governo sobre a proposta de formação do povo através de uma educação higiênica, sem dúvida, uma característica relevante do higienismo nacional. Colaboravam, assim, para a organização de intervenções estatais no campo da Saúde e Educação. Por isso, as tentativas, por certo incipientes, mas presentes do governo imperial em responder algumas demandas sociais, como por exemplo, a escolarização da ginástica.

O higienismo teve também um papel decisivo em um debate mais amplo sobre interpretações, dilemas e rumos da sociedade brasileira. $\mathrm{O}$ povo doente era o grande obstáculo ao progresso ou à civilização, nos termos do início do século XX. (HOCHMAN; LIMA, 1996; HOCHMAN, 1993). 
Com isso podemos observar um movimento pendular entre os intelectuais e higienistas brasileiros. Em outras palavras, um grupo influenciava o outro. Se de um lado, os médicos exigiam do Estado uma atitude construtiva na melhoria das condições de vida da população, de outro, os intelectuais construíam explicações nacionalistas para o atraso do país. Assim, as condições sociais, econômicas e educacionais do povo passaram a ser muito significativas (STEPAN, 2005). Se isto provocou uma mudança na consciência nacional sobre os problemas brasileiros, pouco foi realizado no século XIX pelo Estado na área social brasileira.

Durante todo o século XIX, o Estado teve uma intervenção incipiente, dificultando assim, a execução de projetos higienistas na Educação e Saúde. Dessa maneira, a Ginástica durante os anos oitocentistas teve uma lenta difusão no cenário dos serviços públicos de educação e saúde, como demonstraremos adiante.

\section{Mentalidade higienISTA E Ginástica no Brasil otTocentista}

No Brasil, as preocupações com os cuidados com o corpo e a disseminação de práticas corporais, como a Ginástica, tiveram destaque nas teses exigidas para a concessão do título de doutor nas Faculdades de Medicina do Rio de Janeiro e de Salvador. Uma consequência do aumento da consciência sobre os problemas de saúde da população e da necessidade de saneamento da capital. Neste cenário do século XIX, a Educação Física ainda não era considerada uma disciplina escolar, mas sim um conjunto de cuidados ligados à higiene e à prática de atividades físicas (SOARES, 2000). Por exemplo, uma das primeiras teses sobre Ginástica no Brasil foi defendida na Faculdade de Medicina no Rio de Janeiro, em 1846, pelo médico mineiro Dr. Joaquim Pedro de Mello, intitulada "Generalidades acerca da educação physica dos meninos". Em seus termos:

Todos realmente reconhecem as vantagens, que traz ao corpo o exercício, regularmente feito; e ninguem pôde duvidar por consequencia, quanto influiria sobre o vigor, e robustez dos meninos a creação 
d'um gymnasio, onde a mocidade fosse entregar-se á diversos generos de exercicios. [...] Em nem-um estabelecimento publico de educação, em nem-um collegio se procura tornar a mocidade, que nelles aprende, participante de sua utilidade; nem mesmo no collegio de Pedro $2^{\circ}$, conforme nos consta, se dá importância, que merecem, aos exercícios gymnasticos; embora todos os dias estejamos vendo, que os habitantes das roças, que se lanção francamente á vida activa, superão aos da cidade em força, e agilidade: por que se entre elles falta um gymnasio bem organisado, ha com tudo um campo vasto, e muitos serviços, com que adexírão seos corpos, e que supprem o, que nas cidades é indispensavel. (MELLO, 1846, p.34)

Mello (1846) questionava a falta de intervenção do governo brasileiro na questão da Educação Física, e, sobretudo, apontava para um cenário em que ela, mesmo que presente na escola pública, não tinha a importância desejada pelos médicos na educação das crianças e jovens. Além disso, enfatizava a mentalidade da relação entre urbanização e sedentarismo.

Com o decorrer do século XIX, tivemos algumas iniciativas isoladas que colaboravam para a disseminação da Ginástica nas escolas públicas. Por exemplo, em 1854 foi publicado o "Regulamento do Ensino primário e secundário no município da Corte", nele a Ginástica é incluída entre as disciplinas do ensino primário. Em relação aos termos originais, a Ginástica nas escolas é assim mencionada:

Artigo 47. O ensino primario nas escolas publicas comprehende: A instrucção moral e religiosa, A leitura e escripta, As noções essenciaes da grammatica, Os principios elementares da arithmetica, O systema de pesos e medidas do município. Póde comprehender tambem [...] A geometria elementar, agrimensura, desenho linear, noções de musica exercicios de canto, gymnastica, e hum systema mais desenvolvido de pesos e medidas [...] (BRASIL, 1854, p. 55) 
Outras iniciativas governamentais sucederam-se ainda durante o império em relação ao incentivo à prática da Ginástica. Segundo Carmen Lúcia Soares (2001), em 1879, o ensino da Ginástica se tornou obrigatório na capital brasileira, através do decreto $\mathrm{n}^{\circ} 7247$. Além disso, em 1882, a Comissão Imperial de Instrução Pública, através de parecer do relator Ruy Barbosa, foi favorável à inclusão da Educação Física no sistema de ensino brasileiro (SOARES, 2000). Esse parecer ficou conhecido como uma importante defesa dos benefícios da prática da Educação Física na escola brasileira. Ruy Barbosa, contaminado pelo ideário higienista, mostrou-se um entusiasta da prática da Ginástica. Como podemos observar, essas iniciativas eram iniciais, sem alcançar os objetivos de democratização. Contudo escolas importantes adotaram a Ginástica em seu currículo, não como uma disciplina, mas como uma atividade a ser oferecida aos alunos com objetivos de formação moral e física.

Por exemplo, Cunha Júnior (2003) descreve que o Colégio Pedro II foi fundado em 1837 com o objetivo de oferecer uma formação diferenciada à elite carioca do século XIX. Como colégio oficial se diferenciou com uma formação moderna que incluía em seu currículo saberes desconhecidos dos outros colégios, como a Música, o Desenho e a Ginástica.

Em 1841, seu primeiro professor de Ginástica foi o militar Guilherme Luiz de Taube, contrato pelo reitor Joaquim Caetano da Silva, médico formado em Paris, que foi convencido pelos argumentos higienistas de Taube a introduzir a Ginástica no colégio. (CUNHA JUNIOR, 2003)

A inserção da Ginástica no contexto escolar teve uma relação muito próxima com os objetivos higienistas. De um lado os médicos viam na educação física dos jovens uma estratégia de disciplinarização e de inculcação de hábitos saudáveis. Do outro, os primeiros instrutores viam a medicina como referência científica necessária para legitimar suas práticas. Um bom exemplo desta premissa é um relatório escrito pelo médico Luiz Vicente de Simoni (1792-1881), membro da Sociedade de Medicina do Rio de Janeiro. O documento assinado por ele data de 04 de agosto de 1832, intitulado: 
"Relatorio sobre huma memoria do Sr. Guilherme Luiz Taube acerca dos effeitos physicos e moraes dos exercicios gymnasticos", tinha como objetivo responder a uma demanda do militar Guilherme Luiz de Taube. Experiente na área de Ginástica, Taube solicitou à sociedade médica um atestado de utilidade de suas práticas na educação de crianças e jovens. Nos termos do relatório de Simoni (1832, p. 3-4):

Senhores. - A Memória que o Sr. Guilherme Luiz Taube apresentou a esta Sociedade, e de cujo exame vos dignastes encarregar- me, não he trabalho de hum escriptor que se proponha illustrar esta parte da sciencia, mas sim de hum indivíduo, que, tencionando estabelecer neste paiz huma escola, aonde os exercícios gymnasticos sejão practicados debaixo da sua direcção ; dirige-se a prevenir o publico em favor do seu estabelecimento , e do objecto delle; e que, para accreditar perante o mesmo publico a utilidade physica, o moral delles, assim como a veracidade das asserções com que elle a afliança no seu escripto, recorre a esta Sociedade submittindo ao seu juizo e approvação o mencionado seu trabalho; não para ella julgar da sua perfeição como obra, mas da sua veracidade como peça dirigida a hum publico que pode duvidar dos principios nella expendidos, e da utilidade da instituição que elle sa propõe.

Assim o Sr. Taube não tracta este objecto como hum sábio, nem o desenvolve physiologicamente em toda a extensão de que he susceptível, mas limitase a indicar summariamente e em geral as vantagens physicas e moraes dos exercícios gymnasticos; declarando que vai estabelecer neste paiz huma escola em que êlles serão ensinados, e practicados debaixo da sua direcção, e com os melhores methodos conhecidos. Elle tenciona, como pessoalmente me asseverou, mandar traduzir em nosso idioma, e outros, este seu trabalho que escreveo em inglez por ser para ele a lingua mais facil, depois da sueca sua natural, e manda-lo distribuir juntamente com o parecer que esta Sociedade pronunciar acerca da utilidade da instituição que elle se propõe por elle affiançada.

Movimento, Porto Alegre, v. 19, n. 01, p. 139-159, jan/mar de 2013. 
É interessante percebemos que Taube procurou uma sociedade médica para justificar sua prática. $\mathrm{O}$ parecer da Sociedade de Medicina do Rio de Janeiro servir-lhe-ia como argumento de autoridade para a introdução da Ginástica entre os brasileiros. Quando o Dr. Simoni relata a possível resistência da população sobre os princípios e a utilidade da Ginástica, indicia uma possível posição da opinião pública daquele momento sobre as dúvidas e insuficiente esclarecimento sobre seus benefícios. Foi persistente o discurso legitimador da prática a partir de constatações biológicas, como alude Taube, citado por Simoni (1832, p. 4-5):

Fallando o Sr. Taube das vantagens physicas dos exercicios gymnasticos diz: que estes desenvolvem gradualmente a força muscular, augmentão a energia de todas as funcções do corpo humano, regulão nas crianças o incremento dos differentes órgãos, e mantém a sua acção em hum justo equilíbrio: que augmentando a força dos músculos e dos nervos, elles tendem a dar lhes huma flexibilidade pela qual o menino torna se capaz de executar com força, dextereza e agilidade todos os movimentos de que o seu corpo he susceptível: que a puericia he hum estado de continuo movimento, que senão pode fazer cessar ou interromper se não á custa da saúde, e que os bancos, em que nas escolas ella se acha ordinariamente confinada, são huma violência feita á natureza; e que assim os exercícios gymnasticos offerecem meios poderosos de remediar e prevenir os effeitos da vida sedentaria a que os meninos são muito sujeitos nas grandes cidades.

Fallando dos effeitos moraes, diz: que os órgãos do pensamento, e os membros a elles subordinados tem huma connexão tão intima com o intellecto que do bom estado de hum deve resultar o livre, e inteiro exercicio das funcções do outro: que os exercicios gymnasticos conferem ao homem hum brio, coragem, e energia mui elevada; pois promovem a sua confiança na força que a providencia depara a cada individuo para sua conservação; e que assim o tornão habil, em caso de necessidade, afazer uso da sua força, e empregaria para a conservação dos outros.

Vovimento, Porto Alegre, v. 19, n. 01, p. 139-159, jan/mar de 2013. 
A opção de Taube pela aproximação dos saberes ginásticos com os saberes médicos não era uma tendência local e específica. Taube tinha experiência com o ensino ginástico nos Estados Unidos da América, e era natural da Suécia, berço de uma importante tradição e sistematização da Ginástica elaborada por Per-Henrick Ling (1776-1839) no início do século XIX. Essas novas sistematizações de ginásticas tiveram uma lenta difusão neste período na Europa (VIGARELLO; HOLT, 2008), mas chegavam ao Brasil, também associadas aos saberes médicos e militares, pois o perfil dos instrutores de Ginástica neste período no Brasil se caracterizava por uma biografia ligada à vida militar, e pela origem europeia de seus postulantes. A própria biografia de Taube aproxima-se deste perfil:

[...] O Sr. Taube colheo os conhecimentos que possue nesta materia, nos Estados Unidos da America do Norte, aonde tambem exerceo o cargo de Mestre em hum collegio gymnastico em New York como se deprehende de varias correspondências cujos originaes me confiou. O Sr. Taube he Sueco, e existe já desde algum tempo neste paiz ligado a elle, e aos interesses do mesmo por laços de família, que prendem o seu affecto, e a sua liberdade a huma Orphã Brasileira e pobre, tirada do Recolhimento da Santa Casa, com que elle casou quando, tendo entrado no serviço nacional, como Capitão do Exercito, contava sobre os meios com que podesse sustentar sua família. Desempregado agora, e sem meios, em virtude da Lei geral de 24 de Novembro de 1830; e detido neste paiz pelos ditos laços, procura, pelo estabelecimento que pretende fundar do modo acima indicado, hum honesto meio de subsistência, pondo em uso os conhecimentos que possue na gymnaslica. Esta circunstancia, ainda que puramente individual, e extranha á sciencia, e aos interesses geraes da Nação, e da humanidade de que nos occupamos, não deixa de o recomendar aos nossos corações. (SIMONI, 1832, p.6-7)

Se já esboçamos aqui as intenções de legitimação das práticas de Taube por parte dos médicos, ainda nos interessa a forma como 
os médicos, em específico, a Sociedade de Medicina do Rio Janeiro, através do parecer do Dr. Luiz Vicente de Simoni, posicionou-se sobre a relevância dos exercícios físicos. Para ele:

As vantagens pois da gymnastica não são problemáticas á face da Medicina; ellas são atestadas pela historia, e afiançadas pela sciencia; nada há mais reconhecido, e provado do que ellas. A' opinião favorável dos Medicos de todos os paizes, e de todos os séculos podemos francamente addicionar a nossa, e favorecer com ella a instituição de hum estabelecimento a ella destinado, tal como o que se propõe o Sr. Taube.

Se deste modo concorrermos para a sua realização não só poderemos fazer hum serviço á humanidade pelos benefícios que a gymnastica pode trazer para o melhoramento da saúde dos indivíduos della necessitados, como também ao paiz, ao qual dará huma população mais vigorosa, e mais apta a deffende-lo, quando o amor, e a practica destes exercícios se propaguem, e tornem geraes pela evidencia de suas vantagens. [...]

Em hum paiz como este, no meio de huma profusão de meios que a natureza fornece para o sustento do homem abolido pela froxidão dos tecidos, produzida pelo calor, e humidade do clima; [...] e bom he que a molleza, e a inércia não o tornem inútil á Sociedade. A tendência que o systema lymphatico, e glandular tem a predominar sobre o muscular, he neste paiz larga fonte de muitas moléstias fataes, ao mesmo tempo que o excesso da exaltação cerebral traz á pátria tantos abalos, e desgraças que ella tem de chorar; a influencia da gymnastica pode produzir huma mudança mui salutar, desenvolvendo a força, á actividade, e restabelecendo o equilíbrio dos systhemas organicos, e do incitamento dos seus órgãos pelos effeitos a que ella dá lugar sobre systhemas, e orgams mui differentes; fazendo cessar a preguiça, as enfermidades, e a mania politica que infelizmente não perdem, e hão perder-se quanto antes ellas não forem atalhadas. (SIMONI, 1832, p. 15-16)

Vovimento, Porto Alegre, v. 19, n. 01, p. 139-159, jan/mar de 2013. 
A posição médico-higienista concordava com a organização de um estabelecimento próprio para a prática dos exercícios físicos. Esta iniciativa estabelecida em países como a França e Suécia durante o século XIX, tornou-se proposição de Taube que recebeu incentivo por parte dos médicos. O relatório de 1832, escrito pelo Dr. Simoni, indica ainda que esta instalação deveria ser pública para que muitas pessoas tivessem acesso aos seus benefícios (SIMONI, 1832), ou seja, havia a intenção de disseminação da atividade física como hábito higiênico. Se entre os intelectuais da saúde a prática era benéfica e necessária ao desenvolvimento do país, ainda havia a necessidade de convencimento das autoridades governamentais em relação a sua intervenção no campo. Daí a relevância do caráter social da Ginástica. Nos termos de Simoni (1832, p. 11)

A gymnastica, que tem como fito desenvolver esta força pode pois exercer huma grande influência sobre o caracter, a gloria, e prosperidade de huma nação, e não só ella he capaz de a beneficiar debaixo de hum ponto de vista hygienico, como tambem, social e politico.

Embora pudéssemos entender que o interesse público na introdução de uma educação física fosse razoável, muitos obstáculos se contrapunham a sua efetiva institucionalização. Por exemplo, nas escolas públicas o mais comum era a resistência da elite brasileira em permitir que seus filhos fizessem tarefas físicas, que para eles eram associadas ao trabalho manual: "Em um país que considerava as atividades manuais como algo de menor importância [...], pois o importante era valorizar o intelectual, houve realmente muita dificuldade de implementação de atividades físicas nos currículos das escolas brasileiras". (MELO, 1998, p.54).

Melo (1998) explica que os colégios pioneiros na Educação Física eram colégios particulares e de origem estrangeira. Dentre eles, os que merecem destaque foram os colégios ligados a instituições religiosas, tais como: Colégio Anchieta de Nova Friburgo, Rio de Janeiro, fundado em 1886; Colégio São Luiz, em Itu, São Paulo; Colégio Koelle, Rio Claro, São Paulo; Instituto Granbery, Juiz 
de Fora, Minas Gerais, de 1889; Colégio Reis, Petrópolis, Rio de Janeiro, cadeira de Ginástica de 1881; e por fim, Colégio de Artífices, de São Paulo, com aulas de Ginástica desde 1874.

No final do século XIX, as Escolas Normais, escolas de prestígio com o objetivo de formação de professores, também adotaram a Ginástica no currículo, como exemplo a Escola Normal da Corte, em 1881, no Rio de Janeiro, que teve como professores o Capitão Ataliba M. Fernandes, e posteriormente seu discípulo, Arthur Higgins.

Associada aos discursos legitimadores da Ginástica, a ciência do século XVIII e XIX, com grande prestígio na época, organizava as bases da termodinâmica, da entropia, e por último da microbiologia. Com estas descobertas, hábitos corporais deviam ser reformados, pois a limpeza não estava mais na aparência. $\mathrm{O}$ cuidar do corpo se estabeleceu como uma norma moral. Desse modo, uma educação do corpo seria mais do que tudo uma educação moral, em que a Ginástica e higiene se estabeleciam como ferramentas privilegiadas dos corpos no século XIX. Independentemente, em uma lógica própria e específica, em contextos diferenciados, como por exemplo, na capital do Império em boa parte do século XIX, ou na transição do século XIX para o XX em um contexto republicano, a Ginástica era influenciada pela mesma mentalidade higienista que permaneceu evidente no período estudado.

\section{Considerações finaIS}

A mentalidade higienista colaborou para a lenta difusão da Ginástica no contex to brasileiro do século XIX. Por sua vez, o Estado brasileiro se ocupou de leis que incentivavam a Ginástica, além da introdução de sua prática em instituições governamentais como as escolas e instituições localizadas na capital federal. Mas esta intervenção era ainda incipiente no século XIX para garantir sua disseminação no vasto território brasileiro, como aludiam os médicos. Havia imensas diferenças regionais entre o litoral e o interior, como preconizaram importantes higienistas e intelectuais do fim do século XIX e início do século XX, como, Euclides da Cunha, Alberto Torres, 
Rui Barbosa, Monteiro Lobato, Belisário Penna, Carlos Chagas e Oswaldo Cruz, todos eles preocupados em pensar estratégias de desenvolvimento em um projeto de nação.

Podemos, também, entender ao olhar para a Ginástica do século XIX, no contexto brasileiro, existiu a forte influência de concepções higienistas defendidas por médicos, e sustentadas pela ciência, como argumento de autoridade para uma reforma de hábitos corporais da população. O discurso médico pretendeu convencer os governos sobre a necessidade de intervenção no sentido de incentivar e democratizar hábitos saudáveis. Essa inculcação de práticas corporais passava pela reforma de hábitos defendidos pela higiene que incluíam a Ginástica. 
Gymnastics, hygiene and eugenics in the Brazilian nation project in 19th century

Abstract: The objective of this study was to describe the influence of medical knowledge about the organization of the school gymnastics in the 19th century in Brazil. For this, it used as sources: thesis to obtain the title of Doctor of the Faculty of Medicine of Rio de Janeiro and of Bahia; documents of the National Academy of Medicine and the São Paulo Normal School. He concluded that the hygienist mentality was instrumental in spreading the gymnastics in the Brazilian context.

Key words: Gymnastics. History. Brazil. Hygiene. Eugenics

Gimnasia, higiene y eugenesia en el proyecto nación brasileña en el siglo XIX

Resumen: El objetivo de este estudio fue describir la influencia de los conocimientos médicos acerca de la organización dela gimnasia escolar en el contexto del siglo XIX en Brasil. Para ello, fue utilizado como fuentes: tesis para obtener el grado de doctor en la Facultad de Medicina de Río de Janeiro y Bahía, los documentos de la Academia Nacional de Medicina y la Escuela Normal de São Paulo. Llegó a la conclusión de que la mentalidad higienista fue fundamental en la difusión dela gimnasia en el contexto brasileño.

Palabras-clave: Gimnasia. Historia. Brasil. Higiene. Eugenesia.

\section{REFERÊNCIAS}

ARIÈS, Philippe. A história das mentalidades. In: LE GOFF, Jacques (Org.). A história nova. 5. ed. São Paulo: Martins Fontes, 2005. p. 207-236.

BRASIL. Decreto n. 1331 de 17 de fevereiro de 1854. Approva o regulamento para a reforma do ensino primario e secundario do municipio da Côrte. Colecção das leis do Imperio do Brasil, Rio de Janeiro, v. 17, parte 2, 17 fev. 1854. Secção 12.

CUNHA JUNIOR, Carlos Fernando. Os exercicios gymnasticos no Collegio Imperial de Pedro Segundo (1841-1870). Revista Brasileira de Ciências do Esporte, Campinas, v. 25, n.1, p. 69-81, set./nov. 2003.

Movimento, Porto Alegre, v. 19, n. 01, p. 139-159, jan/mar de 2013. 
DIAS, Patrícia Fortunato. Prevenir é melhor que curar: as especificidades da França nos estudos de Eugenia. 2008. 110 f. Dissertação (Mestrado) Curso de História, Pontifícia Universidade Católica de São Paulo, São Paulo, 2008.

EDLER, Flavio Coelho. A Escola Tropicalista Baiana: um mito de origem da medicina tropical no Brasil. História, Ciências \& Saúde-Manguinhos, Rio de Janeiro, v. 9, n. 2, p. 357-85, maio/ago. 2002.

GONDRA, José G. Artes de civilizar: medicina, higiene e educação escolar na Corte Imperial. Rio de Janeiro: EdUERJ, 2004.

HOCHMAN, Gilberto. Regulando os efeitos da interdependência: sobre as relações entre saúde pública e construção do Estado (Brasil, 1910-1930). Estudos históricos, Rio de Janeiro, v. 6, n. 11, p. 40-61, 1993.

HOCHMAN, Gilberto; LIMA, Nízia Trindade. Condenado pela raça, absolvido pela medicina: o Brasil descoberto pelo Movimento Sanitarista da Primeira república. In: MAIO, M. C; SANTOS, R. V. (Org.). Raça, ciência e sociedade. Rio de Janeiro: Fiocruz, 1996. p. 23-40.

LE GOFF, Jacques. A história nova. 5. ed. São Paulo: Martins Fontes, 2005.

MACHADO, João da Matta. Da educação physica, intellecutal e moral da mocidade do Rio de Janeiro da sua influencia sobre a saúde. 1874. $101 \mathrm{f}$. These (Conclusão de Curso) - Curso de Medicina, Faculdade de Medicina do Rio de Janeiro, Rio de Janeiro: Typ. de G. Leuzinger e Filhos, 1874.

MARQUES, Vera. Medicalização da raça. Campinas: Edunicamp, 1997.

MELLO, Joaquim Pedro de. Generalidades a cerca da educação physica dos meninos. 1846. $43 \mathrm{f}$. These (Conclusão de Curso) - Curso de Medicina, Faculdade de Medicina do Rio de Janeiro, Rio de Janeiro: Typ. de Teixeira e Comp., 1846.

MELO, Victor Andrade. A Educação Física nas escolas brasileiras do século XX: Esporte ou Ginástica? In: FERREIRA NETO, A. Pesquisa histórica na Educação Física. Vitória: UFES, 1998. p. 48-68.

PEIXOTO, Afrânio. Elementos de "Hijiene". Rio de Janeiro, Francisco Alvez, 1913.

RABINBACH, Anson. The Human Motor: fatigue, energies e origins of modernity. Los Angeles: California University, 1992.

SIMONI, Luiz Vicente de. Relatorio sobre huma memoria do Sr. Guilherme Luiz Taube acerca dos effeitos physicos e moraes dos exercicios gymnasticos. Rio de Janeiro: Sociedade de Medicina do Rio de Janeiro, 1832.

SKIDMORE, Thomas. Uma História do Brasil. 2. ed. Rio de Janeiro, Paz e Terra, 1998. 
SOARES, Carmen Lucia. Educação Física, Raízes Européias e Brasil. 2 ed. Campinas: Autores Associados, 2001. 43-60, 2000.

Notas sobre a educação do corpo. Educar em Revista, Curitiba, n. 16, p.

STEPAN, Nancy. A hora da eugenia: raça, gênero e nação na América Latina. Rio de Janeiro: Fiocruz, 2005.

VIGARELLO, Georges; HOLT, Richard. O corpo trabalhado - Ginastas e esportistas no século XIX. In: CORBIN, A.; COURTINE, J.; VIGARELLO, G. História do corpo. Rio de Janeiro: Vozes, 2008. v. 2. p. 393-478.

Endereço para correspondência:

Edivaldo Góis Júnior

Universidade Federal do Rio de Janeiro

Faculdade de Educação

Laboratório de Estudos em Educação do Corpo - Sala 224.

Av. Pasteur, 250 fundos. $2^{\circ}$ andar.

Praia Vermelha - Rio de Janeiro-RJ

CEP 22.290-240

Recebido em: 14.10.2012

Aprovado em: 04.12.2012

Movimento, Porto Alegre, v. 19, n. 01, p. 139-159, jan/mar de 2013. 